Biological Markers and Guided Therapy, Vol. 1, 2014, no. 1, 25 - 38

HIKARI Ltd, www.m-hikari.com

http://dx.doi.org/10.12988/bmgt.2014.3122

\title{
Chronic Fatigue Syndrome/Myalgic
}

\section{Encephalomyelitis and the Potential Role of T Cells}

\author{
S. L. Hardcastle ${ }^{a} *$ E. W. Brenu ${ }^{a}$, D.R. Staines ${ }^{a, b}$, S. Marshall-Gradisnik ${ }^{a}$ \\ a. National Centre for Neuroimmunology and Emerging Diseases \\ Griffith Health Institute, School of Medical Science \\ Griffith University, Gold Coast, QLD, Australia \\ b. Queensland Health, Gold Coast Public Health Unit \\ Robina, Gold Coast, Queensland, Australia
}

Corresponding Author*

Sharni L. Hardcastle BBioMedSc (Hons)

National Centre for Neuroimmunology and Emerging Diseases

Griffith University, Griffith Health Centre

Parklands Drive, Southport, 4222

Telephone: +614075678 0918

Mobile: +61422900733

Copyright (C) 2014 S. L. Hardcastle. This is an open access article distributed under the Creative Commons Attribution License, which permits unrestricted use, distribution, and reproduction in any medium, provided the original work is properly cited.

\begin{abstract}
Chronic Fatigue Syndrome/Myalgic Encephalomyelitis (CFS/ME) is a multifactorial disorder defined by symptom-specific criteria and characterised by severe and prolonged fatigue. CFS/ME typically affects a variety of bodily systems, including the immune system. Patients with CFS/ME exhibit significantly reduced Natural Killer (NK) cell activity suggesting immune which may be hallmarks of changes in the adaptive immune system, potentially including $\mathrm{T}$ cell subsets and function. The principal purpose of $\mathrm{T}$ cells is to regulate immune responses and maintain immune homeostasis. These regulatory measures can often be compromised during illness and may present in a number of diseases including CFS/ME. This review paper examines the role of $\mathrm{T}$ cells in $\mathrm{CFS} / \mathrm{ME}$ and the potential impact of $\mathrm{T}$ cells on CFS/ME immune profiles with an evaluation of the current literature.
\end{abstract}


Keywords: Chronic Fatigue Syndrome, Fatigue, $\mathrm{T}$ cells, $\mathrm{T}$ lymphocyte, Cytokines

\section{Introduction}

The purpose of $\mathrm{T}$ cells is to regulate the immune responses of both innate and adaptive immune cells by maintaining immunological homeostasis, which may often be compromised during illness. Some immunological disorders have also been associated with deficiencies or dysfunction in subtypes of $\mathrm{T}$ cells, such as regulatory $\mathrm{T}$ cells (Tregs) $(1,2)$. Dysfunction in $\mathrm{T}$ cells and their pro- or antiinflammatory cytokines can reduce the ability of these cells to maintain cytokine homeostasis, promote autoimmunity or respond to pathogens (3-7). Imbalances in Th1/Th2/Th17 cytokine profiles have been related to autoimmune diseases, such as multiple sclerosis and rheumatoid arthritis (6, 8-12).

Chronic Fatigue Syndrome/Myalgic Encephalomyelitis (CFS/ME) is a serious illness with consistent immune perturbations (13-20). Patients diagnosed with CFS/ME primarily experience persistent fatigue, physically and mentally, for a period of at least 6 months. Other symptoms include headaches, dizziness, muscle pain, pallor, abdominal pain, nausea and swollen lymph nodes $(21,22)$. CFS/ME patients may in some cases present with altered susceptibility for infections, indicative of chronic low-grade inflammation and potential dysregulation in $\mathrm{T}$ cells (23). Currently, many $\mathrm{T}$ cell studies in CFS have inconsistent results and it remains to be determined if these cells have a possible role in the pathology of CFS/ME patients (13-20), hence this review aims to examine T cells in CFS/ME.

\section{T Cells}

$\mathrm{T}$ cells are lymphocytes of the adaptive immune system that play an important role in cell-mediated immunity as they respond to antigens released during inflammation or tumour invasion after being recruited by soluble proteins presented by dendritic cells (DCs), macrophages and neutrophils (24). T cell subsets can be identified based on the expression of surface markers and specific cytokine secretion (25-28).

All $\mathrm{T}$ cells originate from the bone marrow and populate the thymus as hematopoietic progenitor cells (HPCs) which differentiate into immature thymocytes $(27,29)$. Thymic lymphoid progenitors can develop into either $\alpha \beta$ or $\gamma \delta \mathrm{T}$ cells as a result of TCR chain rearrangement, with the majority of heterodimers forming the $\alpha \beta \mathrm{T}$ cell lineage ( 98\%) (30). $\alpha \beta$ T cells then develop into $\mathrm{CD}^{+} \mathrm{CD}^{+}$or $\mathrm{CD}^{+} \mathrm{CD}^{+}{ }^{+} \mathrm{T}$ cells which selectively recognise and bind to molecules MHC class II and I respectively or NKT cells $(7,31,32)$. 


\section{CD4 $^{+}$T Cells}

$\mathrm{CD} 4^{+} \mathrm{T}$ cells coordinate the activity of both innate and adaptive immune systems (25). Naive $\mathrm{CD}^{+}$effector $\mathrm{T}$ cells differentiate into distinct lineages following activation by NK cells and DCs and differentiate into Tregs, Th1, Th2 and Th17 subsets (25).

Th1 effector $\mathrm{CD}^{+} \mathrm{T}$ cells are responsible for cell-mediated immunity and identified predominantly based on their production of pro-inflammatory cytokines, IFN- $\gamma$, LT- $\alpha /$ TNF- $\beta$ and IL-2 (3, 5, 7, 12). IFN- $\gamma$ stimulates macrophages to phagocytose pathogens (33-36) and IL-2 importantly regulates and induces the differentiation and proliferation of $\mathrm{T}$ cells, memory $\mathrm{T}$ cells and NK cells (33-36).

Th17 cells cells also secrete pro-inflammatory cytokines, IL-17A, IL-17F, IL-21, IL-22, IL-26 and TNF- $\alpha(3,7,37)$ and enhance host protection against extracellular bacteria, fungi and microbes as well as improving the clearance of intracellular pathogens (5). Th17 cells also secrete chemokines CCL2, CCL3 and CCL20 to allow for the migration of monocytes, T cells and neutrophils towards necessary sites for inflammatory responses $(3,7,37)$. IL-17 from Th17 cells is involved in the development of immune-related diseases, such as Autoimmune Arthritis and Multiple Sclerosis, and is also amplified in patients with asthma and rheumatoid arthritis $(34,36)$. Regulation of pro- and anti-inflammatory cytokines is important for immune-related responses and cytokine shift either towards a Th1/Th17 or Th2 cytokine profile may underlie certain disorders, including CFS/ME $(4,9,35)$.

Th2 cells are responsible for extracellular pathogen immunity, producing antiinflammatory cytokines, including IL-4, IL-5, IL-9, IL-10, IL-13 and IL-25 (3, 7, 27). IL-5 and IL-9 are important in immune response to allergic reactions while IL-4 and IL-10 regulate inflammatory responses (7). Shifts towards a Th2 mediated immune response may encourage chronic inflammation, as observed in disorders such as Multiple Sclerosis, Rheumatoid Arthritis and Gulf War Illness $(6,9-11,13,18)$.

\section{T Regulatory Cells}

Tregs are a subset of $\mathrm{CD}^{+} \mathrm{T}$ cells, distinguished by their functional ability to suppress immune responses and prevent autoimmunity $(27,38,39)$. There are two main $\mathrm{CD}^{+}$Tregs, iTregs which develop from naïve $\mathrm{CD}^{+} \mathrm{T}$ cells in peripheral lymphoid tissues and intrathymic nTregs $(27,39)$. Foxp3 is an important transcription factor in iTregs and nTregs, which regulate pro-inflammatory factors by suppressing both IL- 2 and IFN- $\gamma(37,40)$. IL- 4 , IL-10 and TGF- $\beta$ induce the generation of iTreg cells from naïve $\mathrm{CD}^{+} \mathrm{T}$ cells (26). The iTreg subset of $\mathrm{T}$ cells includes further subsets such as type 1 Tregs $(\operatorname{Tr} 1)$ and Th3 cells which variably express Foxp3 $(26,28)$. iTregs mediate inhibitory function by producing suppressive anti-inflammatory cytokines, IL-5, IL-10, TGF- $\beta$ and IFN- $\gamma$ 
(predominantly IL-10 and TGF- $\beta$ ) $(26,38)$. Impairments in Treg development and function, including diminished Foxp3 expression, can also be related to autoimmune diseases (41).

\section{$\mathrm{CD8}^{+} \mathrm{T}$ Cells}

$\mathrm{CD}^{+} \mathrm{T}$ cells are functionally important for both innate and adaptive immunity (42). $\mathrm{CD}^{+} \mathrm{T}$ cells protect the body from foreign or invading microorganisms by recognising diverse antigens presented by MHCI peptides. This stimulates CD8 ${ }^{+}$ $\mathrm{T}$ cell proliferation, cytokine (IFN- $\gamma$ and TNF) and chemokine (IL-8) secretion and lysis of infected cells $(42,43) . \mathrm{CD}^{+} \mathrm{T}$ cells also produce lytic proteins (such as granzyme B and perforin) (43).

Cytotoxic $\mathrm{CD}^{+} \mathrm{T}$ cells express high quantities of granzymes, perforin, cytokines and chemokine's (42-45). The cytotoxic pathways of $\mathrm{CD} 8^{+} \mathrm{T}$ cells allow defence against virus-infected or transformed cells through MHCI recognition $(46,47)$. Perforin and granzymes exocytose from $\mathrm{CD} 8^{+} \mathrm{T}$ cells to induce apoptosis of target cells (46). Perforin is a membrane-disrupting protein, secreted during an immune response, which enters the membrane of a target cell, allowing granzymes to enter. Once inside, granzymes cleave caspases and degrade the DNA of target cells, promoting an apoptotic cascade (46). Aside from perforin and granzyme secretion, target-cell death receptors, such as Fas (CD95) can also induce caspasedependent apoptosis in target cells (46). The role of $\mathrm{CD}^{+} \mathrm{T}$ cells and their maintenance of inflammation may be associated with autoimmune disease (47, 48), incidentally, increases in $\mathrm{CD}^{+} \mathrm{T}$ cells, perforin and granzyme $\mathrm{B}$, may be related to diseases such as Lupus (48).

\section{T Cells in CFS/ME}

$\mathrm{CFS} / \mathrm{ME}$ is a diverse multisystem illness with varied symptom severity that can substantially affect a person's way of life (21). There are substantial costs associated with CFS/ME worldwide and there is no known cure, successful treatments and or useful diagnostic method. Most patients with CFS/ME are incapable of maintaining full-time occupations while the more severe cases require constant daily assistance (49).

The estimated prevalence rate of CFS/ME is $0.2-0.7 \%$ (49) with women being more greatly affected by CFS/ME then men by up to $80 \%(16,50)$. Of those diagnosed with CFS/ME, approximately $83 \%$ report gradual onset of the disorder while $17 \%$ experience sudden onset, highlighting potential subgrouping based on the onset of CFS/ME (50). Immune investigations in CFS/ME have identified variations in immune cell numbers, significantly reduced lymphocyte cytotoxic activity, decreased neutrophil respiratory burst, fluctuations in cytokine distribution with particular shifts in Th1/Th2 related cytokines and altered expression of immune related genes $(13-20,51,52)$. 
Many studies have examined $\mathrm{T}$ cells in CFS/ME, particularly overall $\mathrm{T}$ cell numbers, $\mathrm{CD}^{+}$and $\mathrm{CD} 8^{+} \mathrm{T}$ cells, with inconsistent results. Some studies found decreases in the number of $\mathrm{CD}^{+} \mathrm{T}$ cells $(18,53)$, while others concluded that there were increases [55]. Similar variations in results have been discovered regarding the $\mathrm{CD}^{+}$subset of $\mathrm{T}$ cells where decreases in the number of $\mathrm{CD} 8^{+} \mathrm{T}$ cells were found in some studies (53-55) while another found increases in $\mathrm{CD}^{+} \mathrm{T}$ cell subsets (56).

Only one study has examined cytokine production in isolated $\mathrm{CD}^{+} \mathrm{T}$ cells in CFS/ME patients and it was found that IFN- $\gamma$ was significantly reduced in CFS/ME patients (4). In CFS/ME patients, variable levels of Th1 cytokines and IFN- $\gamma$ may potentially explain the constant infections and increased inflammation experienced by CFS/ME patients $(18,35)$. The potential increase in secretion or presence of IFN- $\gamma$ specifically may lead to autoimmune related immune responses $(4,10,18,21,35)$.

Isolated $\mathrm{CD} 4^{+} \mathrm{T}$ cells and subsets may provide definitive results thereby reducing the interference from other potential producers of cytokines. Most CFS/ME cytokine studies did not use this technique hence the cytokine data is representative of the whole PBMC population and a number of studies on these cytokines have been measured in CFS/ME patients (IL-2, IL-4, IL-5, IL-6, IL-10, IL-12, IL-13, TNF- $\alpha$, TNF- $\beta$, IFN- $\gamma$ and TGF- $\beta$ ), producing inconsistent results $(4,16,57,58)$. These studies have highlighted potential dysregulation in the CFS/ME cytokine profile by demonstrating significant shifts in cytokines in CFS/ME. Although majority of these studies measured cytokines in PBMCs, irrespective of this, cytokine production in CFS/ME may be indicative of the cytokine profile of $\mathrm{T}$ cells in CFS/ME and potential shifts between Th1/Th2/Th17 regulations.

IL-2 levels have been inconsistent in CFS/ME participants. IL-2 plays an important role in the maintenance of natural immunological self-tolerance with impairments in IL-2 leading autoimmune gastritis, early onset diabetes and T-cell mediated autoimmune diseases such as thyroiditis and severe neuropathy $(16,59)$. IL-2 also contributes to the induction of NK cytotoxic activity $(60,61)$, therefore alterations in pro-inflammatory IL-2 levels may potentially correlate with consistently significant reduced NK numbers and activity in CFS/ME $(15,16,23$, $48,50-52$ ).

The levels of cytokines TGF- $\beta$ and IL- 6 are sometimes raised in patients with CFS/ME (40, 52, 62). Elevated levels of TGF- $\beta$ and IL-6 in CFS/ME patients promote the production of Th17 cells by inducing STAT3, necessary for Th17 cell differentiation (63). Th17 cells produce IL-17 which contributes to disease pathogenesis by acting as a potent pro-inflammatory mediator and is inconsistent in CFS/ME (64). IL-17 enhances autoimmune inflammation by acting on APCs to signal IL-1, IL-6, IL-23 and TGF- $\beta$, factors for pathogenic Th17 development and resulting in exacerbation of autoimmunity $(54,65)$. An increased expression of 
IL-17 cytokines (such as IL-17A), has been linked to a number of autoimmune, immune and inflammatory related diseases, including Rheumatoid Arthritis, Lupus and Asthma $(16,54)$. Similarly, a decrease in Th17 and particularly IL-17 may be related to a reduced host protection mechanism and clearance of pathogens (5) .

Th2 T cells are responsible for the secretion of anti-inflammatory cytokines, such as IL-4 and IL-10. When isolated $\mathrm{CD}^{+} \mathrm{T}$ cells were analysed in CFS/ME patients, no significant changes were found in IL-4 cytokine levels (4). In whole blood, CFS/ME patients have significantly increased expression of the antiinflammatory cytokine IL-10. IL-10 stimulates the production and survival of B cells as well as antibody production and down regulating Th1/Th17 proinflammatory cytokines (66). Infection is the primary promoter of the production of IL-10 producing cells, suggesting that an increase in IL-10 in CFS/ME patients could reflect the chronic infection typically experienced by CFS/ME patients (17, 67). IL-10 also influences signalling of $T$ cells with $B$ cells and may alter $T$ cell responses necessary to autoimmune diseases (66). Assessment of such cytokines in isolated $\mathrm{T}$ cells in CFS/ME patients can provide further insight into dysregulation and cytokine profiles in the disorder.

TGF- $\beta$ is the only cytokine examined unique to iTregs and has been up regulated in CFS/ME patients (63). TGF- $\beta$ is primarily an immunosuppressive cytokine which down regulates the inflammatory response through the inhibition of proinflammatory cytokines $(68,69)$. TGF- $\beta$ deficiencies may promote excessive lymphocyte activation and differentiation, cell adhesion molecule expression, Treg functioning and cell apoptosis, therefore in CFS/ME it is possible that increases in TGF- $\beta$ may reflect an increase in Treg suppression or Treg related activities in CFS/ME (68). Incidentally, significantly increased levels of $\mathrm{CD} 4^{+} \mathrm{CD} 25^{+} \mathrm{FOXP} 3^{+}$cells have been found in CFS/ME patients (70). Regulation and maintenance of immunological tolerance and inflammatory responses can be maintained by Tregs $(1,2,45)$. Hence, deficiencies or dysfunctions of Tregs or the subtypes of Tregs may promote auto reactive immune responses resulting in autoimmune diseases $(1,2)$. Increased $\mathrm{FOXP}^{+}$is typically observed in various forms of cancer (71).

Significantly reduced cytotoxic activity is an important hallmark of CFS/ME, with many CFS/ME patients demonstrating significant reductions NK cell cytotoxic activity $(13,14,17,18)$. Recent studies have identified significant reductions in the cytotoxic activity of isolated $\mathrm{CD}^{+} \mathrm{T}$ cells (14). Although, the underlying causal factor stimulating this effect is unknown, it presupposes that CFS/ME patients are potentially compromised due to failures in this cytotoxic mechanism, possibly relatable to the function of cytotoxic granules and subsequent cytokines in these $\mathrm{T}$ cells. Incidentally, reductions in perforin and granzymes have been reported in CFS/ME $(14,46,72)$. Perforin and granzymes are lytic proteins that ensure effective lysis of viral or microbial pathogens (73). Reductions in perforin 
lead to significant declines in apoptosis of target cells $(73,74)$. Perforin levels are severely decreased in systemic juvenile idiopathic arthritis, instigating defective cytotoxicity in $\mathrm{T}$ cells (75). In contrast, elevated concentrations of perforin are reported in chronic inflammatory disorders with autoimmune features, such as multiple sclerosis and autoimmune thyroid disease. Perforin is significantly increased in inflammatory disorders although the role in these disorders is undefined, it may be indicative of increased cytolytic activity or an immune reaction aimed at removing inflammatory cells (76).

Alterations in the levels of perforin can incidentally affect the release of other lytic proteins, such as granzymes. Granzyme A expression is significantly decreased in $\mathrm{CD}^{+} \mathrm{T}$ cells in CFS/ME patients (14). Granzyme A specifically induces the breakage of single-strand DNA and the nuclear lamina. Therefore, decreases in granzyme A in CFS/ME patients may lead to a reduced ability of the cells to induce target cell death $(77,78)$.

$\mathrm{T}$ cell perturbations may potentially be attributing to alterations $\mathrm{T}$ cell subtypes, fluctuations in $\mathrm{T}$ cell cytokine production, decreases in cytotoxic activity and differential expression of immune related genes in CFS/ME patients.

\section{Conclusion}

A number of studies have assessed $\mathrm{T}$ cells in CFS/ME, although further studies are required to obtain consistency and validation of results. Assessment of $\mathrm{T}$ cell cytokines in CFS/ME patients based on PBMCs is not the most appropriate method of assessing these cells as they are not specific to subsets of $\mathrm{T}$ cells that vary in cytokine secretion. Similarly, assessment of $\mathrm{CD}^{+} \mathrm{T}$ and $\mathrm{CD} 4^{+} \mathrm{T}$ cells and cytokine profiles, may highlight specific cells that may be affected in CFS/ME patients. In particular, Tregs and their regulatory activities may deserve closer investigation. Subgrouping of CFS/ME patients may be necessary in the future to determine whether $\mathrm{T}$ cell subsets and function differs among CFS/ME patients based on their variation of disorder onset or severity.

\section{Acknowledgements}

Mason Foundation

Alison Hunter Memorial Foundation

Queensland Government Smart Futures Fund

\section{Competing Interests}

The authors declare that they have no competing interests. 


\section{References}

1. Sakaguchi S. Naturally arising Foxp3-expressing CD25+ CD4+ regulatory $\mathrm{T}$ cells in immunological tolerance to self and non-self. Nature immunology. 2005;6(4):345-52.

2. Shevach EM. CD4+ CD25+ suppressor T cells: more questions than answers. Nature Reviews Immunology. 2002;2(6):389-400.

3. Murphy KM, Reiner SL. The lineage decisions of helper T cells. Nature Reviews Immunology. 2002;2(12):933-44.

4. Visser J, Blauw B, Hinloopen B, Brommer E, de Kloet ER, Kluft C, et al. CD4 T lymphocytes from patients with chronic fatigue syndrome have decreased interferon- $\gamma$ production and increased sensitivity to dexamethasone. Journal of Infectious Diseases. 1998;177(2):451-4.

5. Weaver CT, Hatton RD, Mangan PR, Harrington LE. IL-17 family cytokines and the expanding diversity of effector $\mathrm{T}$ cell lineages. Annu Rev Immunol. 2007;25:821-52.

6. Yamane H, Zhu J, Paul WE. Independent roles for IL-2 and GATA-3 in stimulating naive $\mathrm{CD} 4+\mathrm{T}$ cells to generate a Th2-inducing cytokine environment. The Journal of experimental medicine. 2005;202(6):793-804.

7. Zhu J, Paul WE. CD4 T cells: fates, functions, and faults. Blood. 2008;112(5):1557-69.

8. Drulovic J, Savic E, Pekmezovic T, Mesaros S, Stojsavljevic N, Dujmovic-Basuroski I, et al. Expression of $\mathrm{T}<\mathrm{sub}>\mathrm{H}</$ sub $>1$ and $\mathrm{T}<\mathrm{sub}>$ $\mathrm{H}</$ sub $>17$ cytokines and transcription factors in multiple sclerosis patients: Does baseline T-Bet mRNA predict the response to interferon-beta treatment? Journal of neuroimmunology. 2009;215(1):90-5.

9. Nevala WK, Vachon CM, Leontovich AA, Scott CG, Thompson MA, Markovic SN. Evidence of systemic Th2-driven chronic inflammation in patients with metastatic melanoma. Clinical Cancer Research. 2009;15(6):1931-9.

10. Peakman M, Skowera A, Hotopf M. Immunological dysfunction, vaccination and Gulf War illness. Philosophical Transactions of the Royal Society B: Biological Sciences. 2006;361(1468):681-7.

11. Singh R, Aggarwal A, Misra R. Th1/Th17 cytokine profiles in patients with reactive arthritis/undifferentiated spondyloarthropathy. The Journal of rheumatology. 2007;34(11):2285-90. 
12. Zabrodskii P, Germanchuk V, Mandych V, Kadushkin A. Role of Th1 and Th2 lymphocytes and cytokines produced by these cells in suppression of immune reactions during subacute poisoning with anticholinesterase toxicants. Bulletin of experimental biology and medicine. 2007;144(1):57-9.

13. Brenu EW, Staines DR, Baskurt OK, Ashton KJ, Ramos SB, Christy RM, et al. Immune and hemorheological changes in chronic fatigue syndrome. Journal of translational medicine. 2010;8(1):1.

14. Brenu EW, van Driel ML, Staines DR, Ashton KJ, Ramos SB, Keane J, et al. Immunological abnormalities as potential biomarkers in chronic fatigue syndrome/myalgic encephalomyelitis. J Transl Med. 2011;9:81.

15. Broderick G, Fuite J, Kreitz A, Vernon SD, Klimas N, Fletcher MA. A formal analysis of cytokine networks in chronic fatigue syndrome. Brain, behavior, and immunity. 2010;24(7):1209-17.

16. Fletcher MA, Zeng XR, Barnes Z, Levis S, Klimas NG. Plasma cytokines in women with chronic fatigue syndrome. J Transl Med. 2009;7:96.

17. Klimas NG, Broderick G, Fletcher MA. Biomarkers for chronic fatigue. Brain, behavior, and immunity. 2012;26(8):1202-10.

18. Klimas NG, Salvato FR, Morgan R, Fletcher MA. Immunologic abnormalities in chronic fatigue syndrome. Journal of clinical microbiology. 1990;28(6):1403-10.

19. Skowera A, Cleare A, Blair D, Bevis L, Wessely S, Peakman M. High levels of type 2 cytokine-producing cells in chronic fatigue syndrome. Clinical \& Experimental Immunology. 2004;135(2):294-302.

20. Swanink CM, Vercoulen JH, Galama JM, Roos MT, Meyaard L, van der Ven-Jongekrijg J, et al. Lymphocyte subsets, apoptosis, and cytokines in patients with chronic fatigue syndrome. Journal of Infectious Diseases. 1996;173(2):4603 .

21. Fukuda K, Straus SE, Hickie I, Sharpe MC, Dobbins JG, Komaroff A. The chronic fatigue syndrome: a comprehensive approach to its definition and study. Annals of internal medicine. 1994;121(12):953-9.

22. Jason LA, Torres-Harding SR, Jurgens A, Helgerson J. Comparing the Fukuda et al. criteria and the Canadian case definition for chronic fatigue syndrome. Journal of Chronic Fatigue Syndrome. 2004;12(1):37-52. 
23. Maes M, Mihaylova I, Leunis J-C. Increased serum IgA and IgM against LPS of enterobacteria in chronic fatigue syndrome (CFS): indication for the involvement of gram-negative enterobacteria in the etiology of CFS and for the presence of an increased gut-intestinal permeability. Journal of affective disorders. 2007;99(1):237-40.

24. Broere F, Apasov SG, Sitkovsky MV, van Eden W. A2 T cell subsets and T cell-mediated immunity. Principles of Immunopharmacology: Springer; 2011. p. 15-27.

25. Harrington LE, Mangan PR, Weaver CT. Expanding the effector CD4 Tcell repertoire: the Th17 lineage. Current opinion in immunology. 2006;18(3):349-56.

26. Jonuleit $\mathrm{H}$, Schmitt E. The regulatory $\mathrm{T}$ cell family: distinct subsets and their interrelations. The Journal of Immunology. 2003;171(12):6323-7.

27. Weaver CT, Harrington LE, Mangan PR, Gavrieli M, Murphy KM. Th17: an effector $\mathrm{CD} 4 \mathrm{~T}$ cell lineage with regulatory $\mathrm{T}$ cell ties. Immunity. 2006;24(6):677-88.

28. Curotto de Lafaille MA, Lafaille JJ. Natural and Adaptive Foxp3< sup $>+</$ sup $>$ Regulatory T Cells: More of the Same or a Division of Labor? Immunity. 2009;30(5):626-35.

29. Schmitt TM, Zúñiga-Pflücker JC. Induction of T cell development from hematopoietic progenitor cells by delta-like-1 in vitro. Immunity. 2002;17(6):74956.

30. Caccamo N, Meraviglia S, Ferlazzo V, Angelini D, Borsellino G, Poccia $\mathrm{F}$, et al. Differential requirements for antigen or homeostatic cytokines for proliferation and differentiation of human $\mathrm{V} \gamma 9 \mathrm{~V} \delta 2$ naive, memory and effector $\mathrm{T}$ cell subsets. European journal of immunology. 2005;35(6):1764-72.

31. Starr TK, Jameson SC, Hogquist KA. Positive and negative selection of T cells. Annual review of immunology. 2003;21(1):139-76.

32. Zúñiga-Pflücker JC, Lenardo MJ. Regulation of thymocyte development from immature progenitors. Current opinion in immunology. 1996;8(2):215-24.

33. Huenecke S, Zimmermann SY, Kloess S, Esser R, Brinkmann A, Tramsen $\mathrm{L}$, et al. IL-2-driven regulation of NK cell receptors with regard to the distribution of CD16+ and CD16-subpopulations and in vivo influence after haploidentical NK cell infusion. Journal of Immunotherapy. 2010;33(2):200-10. 
34. Mocikat R, Braumüller H, Gumy A, Egeter O, Ziegler H, Reusch U, et al. Natural Killer Cells Activated by MHC Class $\mathrm{I}<$ sup $>$ Low $</$ sup $>$ Targets Prime Dendritic Cells to Induce Protective CD8 $\mathrm{T}$ Cell Responses. Immunity. 2003;19(4):561-9.

35. Patarca-Montero R, Antoni M, Fletcher MA, Klimas NG. Cytokine and other immunologic markers in chronic fatigue syndrome and their relation to neuropsychological factors. Applied Neuropsychology. 2001;8(1):51-64.

36. Rham Cd, Ferrari-Lacraz S, Jendly S, Schneiter G, Dayer J-M, Villard J. The pro-inflammatory cytokines IL-2, IL-15 and IL-21 modulate the repertoire of mature human natural killer cell receptors. Arthritis Research and Therapy. 2007;9(6):R125.

37. Zhang $\mathrm{W}$, Dang E, Shi X, Jin L, Feng Z, Hu L, et al. The proinflammatory cytokine IL-22 up-regulates keratin 17 expression in keratinocytes via STAT3 and ERK1/2. PLoS One. 2012;7(7):e40797.

38. Bluestone JA, Abbas AK. Natural versus adaptive regulatory $\mathrm{T}$ cells. Nature Reviews Immunology. 2003;3(3):253-7.

39. Hori S, Nomura T, Sakaguchi S. Control of regulatory T cell development by the transcription factor Foxp3. Science. 2003;299(5609):1057-61.

40. Yang L, Anderson DE, Baecher-Allan C, Hastings WD, Bettelli E, Oukka M, et al. IL-21 and TGF-\&bgr; are required for differentiation of human TH17 cells. Nature. 2008;454(7202):350-2.

41. Nouri-Aria KT. Foxp3 expressing regulatory T-cells in allergic disease. Forkhead Transcription Factors: Springer; 2010. p. 180-93.

42. Berg RE, Forman J. The role of CD8 T cells in innate immunity and in antigen non-specific protection. Current opinion in immunology. 2006;18(3):33843.

43. Belz GT, Kallies A. Effector and memory CD8 $<$ sup $>+</$ sup $>$ T cell differentiation: toward a molecular understanding of fate determination. Current opinion in immunology. 2010;22(3):279-85.

44. Appay V, van Lier RA, Sallusto F, Roederer M. Phenotype and function of human $\mathrm{T}$ lymphocyte subsets: consensus and issues. Cytometry Part A. 2008;73(11):975-83. 
45. Mempel TR, Pittet MJ, Khazaie K, Weninger W, Weissleder R, von Boehmer H, et al. Regulatory $\mathrm{T}$ cells reversibly suppress cytotoxic $\mathrm{T}$ cell function independent of effector differentiation. Immunity. 2006;25(1):129-41.

46. Trapani JA, Smyth MJ. Functional significance of the perforin/granzyme cell death pathway. Nature Reviews Immunology. 2002;2(10):735-47.

47. Deckert M, Sanchez-Ruiz M, Brunn A, Schluter D. Role of CD8 T-cellmediated autoimmune diseases of the central nervous system. Critical Reviews ${ }^{\mathrm{TM}}$ in Immunology. 2010;30(4).

48. Blanco P, Pitard V, Viallard JF, Taupin JL, Pellegrin JL, Moreau JF. Increase in activated CD8+ T lymphocytes expressing perforin and granzyme B correlates with disease activity in patients with systemic lupus erythematosus. Arthritis \& Rheumatism. 2005;52(1):201-11.

49. Toulkidis V. Chronic Fatigue Syndrome. Med J Aust. 2002;176(9):17-55.

50. Reeves WC, Wagner D, Nisenbaum R, Jones JF, Gurbaxani B, Solomon $\mathrm{L}$, et al. Chronic fatigue syndrome-a clinically empirical approach to its definition and study. BMC medicine. 2005;3(1):19.

51. Caligiuri M, Murray C, Buchwald D, Levine H, Cheney P, Peterson D, et al. Phenotypic and functional deficiency of natural killer cells in patients with chronic fatigue syndrome. The Journal of Immunology. 1987;139(10):3306-13.

52. Brenu EW, van Driel ML, Staines DR, Ashton KJ, Hardcastle SL, Keane $\mathrm{J}$, et al. Longitudinal investigation of natural killer cells and cytokines in chronic fatigue syndrome/myalgic encephalomyelitis. J Transl Med. 2012;10:88.

53. Lloyd AR, Wakefield D, Boughton C, Dwyer J. Immunological abnormalities in the chronic fatigue syndrome. The Medical Journal of Australia. 1989;151(3):122.

54. Barker E, Fujimura SF, Fadem MB, Landay AL, Levy JA. Immunologic abnormalities associated with chronic fatigue syndrome. Clinical Infectious Diseases. 1994;18(Supplement 1):S136-S41.

55. Hanson S, Gause W, Natelson B. Detection of immunologically significant factors for chronic fatigue syndrome using neural-network classifiers. Clinical and diagnostic laboratory immunology. 2001;8(3):658-62.

56. Nijs J, De Becker P, De Meirleir K, Demanet C, Vincken W, Schuermans $\mathrm{D}$, et al. Associations between bronchial hyperresponsiveness and immune cell parameters in patients with chronic fatigue syndrome. CHEST Journal. 2003;123(4):998-1007. 
57. Patarca R. Cytokines and chronic fatigue syndrome. Annals of the New York Academy of Sciences. 2001;933(1):185-200.

58. Lloyd A, Pender H. The economic impact of chronic fatigue syndrome. The Medical Journal of Australia. 1992;157(9):599.

59. Setoguchi R, Hori S, Takahashi T, Sakaguchi S. Homeostatic maintenance of natural Foxp3+ CD25+ CD4+ regulatory $\mathrm{T}$ cells by interleukin (IL)-2 and induction of autoimmune disease by IL-2 neutralization. The Journal of experimental medicine. 2005;201(5):723-35.

60. Henney CS, Kuribayashi K, Kern DE, Gillis S. Interleukin-2 augments natural killer cell activity. 1981.

61. Siegel JP, Sharon M, Smith PL, Leonard WJ. The IL-2 receptor beta chain (p70): role in mediating signals for LAK, NK, and proliferative activities. Science. 1987;238(4823):75-8.

62. Zhou L, Chong MM, Littman DR. Plasticity of CD4 $<$ sup $>+</$ sup $>$ T Cell Lineage Differentiation. Immunity. 2009;30(5):646-55.

63. Qin H, Wang L, Feng T, Elson CO, Niyongere SA, Lee SJ, et al. TGF- $\beta$ promotes Th17 cell development through inhibition of SOCS3. The Journal of Immunology. 2009;183(1):97-105.

64. Wynn TA. TH-17: a giant step from TH1 and TH2. Nature immunology. 2005;6(11):1069-70.

65. Cua DJ, Tato CM. Innate IL-17-producing cells: the sentinels of the immune system. Nature Reviews Immunology. 2010;10(7):479-89.

66. Lee M-S, Mueller R, Wicker LS, Peterson LB, Sarvetnick N. IL-10 is necessary and sufficient for autoimmune diabetes in conjunction with NOD MHC homozygosity. The Journal of experimental medicine. 1996;183(6):2663-8.

67. Couper KN, Blount DG, Riley EM. IL-10: the master regulator of immunity to infection. The Journal of Immunology. 2008;180(9):5771-7.

68. Aoki CA, Borchers AT, Li M, Flavell RA, Bowlus CL, Ansari AA, et al. Transforming growth factor $\beta$ (TGF- $\beta$ ) and autoimmunity. Autoimmunity reviews. 2005;4(7):450-9.

69. Letterio JJ, Geiser AG, Kulkarni AB, Dang H, Kong L, Nakabayashi T, et al. Autoimmunity associated with TGF-beta1-deficiency in mice is dependent on MHC class II antigen expression. Journal of Clinical Investigation. 1996;98(9):2109. 
70. Baumgarth N, Tung JW, Herzenberg LA, editors. Inherent specificities in natural antibodies: a key to immune defense against pathogen invasion. Springer seminars in immunopathology; 2005: Springer.

71. Lu H. FOXP3 expression and prognosis: role of both the tumor and $\mathrm{T}$ cells. Journal of Clinical Oncology. 2009;27(11):1735-6.

72. Saiki T, Kawai T, Morita K, Ohta M, Saito T, Rokutan K, et al. Identification of marker genes for differential diagnosis of chronic fatigue syndrome. Molecular Medicine. 2008;14(9-10):599.

73. Chattopadhyay PK, Betts MR, Price DA, Gostick E, Horton H, Roederer $\mathrm{M}$, et al. The cytolytic enzymes granyzme A, granzyme B, and perforin: expression patterns, cell distribution, and their relationship to cell maturity and bright CD57 expression. Journal of leukocyte biology. 2009;85(1):88-97.

74. Capitini CM, Nasholm NM, Duncan BB, Guimond M, Fry TJ. Graftversus-host disease impairs vaccine responses through decreased CD4+ and CD8+ $\mathrm{T}$ cell proliferation and increased perforin-mediated $\mathrm{CD} 8+\mathrm{T}$ cell apoptosis. The Journal of Immunology. 2013;190(3):1351-9.

75. Wulffraat N, Rijkers G, Elst E, Brooimans R, Kuis W. Reduced perforin expression in systemic juvenile idiopathic arthritis is restored by autologous stem-cell transplantation. Rheumatology. 2003;42(2):375-9.

76. Arnold V, Balkow S, Staats R, Matthys H, Luttmann W, Virchow Jr JC. Increase in perforin-positive peripheral blood lymphocytes in extrinsic and intrinsic asthma. American journal of respiratory and critical care medicine. 2000;161(1):182-6.

77. Brenu EW, Ashton KJ, van Driel M, Staines DR, Peterson D, Atkinson $\mathrm{GM}$, et al. Cytotoxic lymphocyte microRNAs as prospective biomarkers for chronic fatigue syndrome/myalgic encephalomyelitis. Journal of affective disorders. 2012;141(2):261-9.

78. Wu H, Neilson JR, Kumar P, Manocha M, Shankar P, Sharp PA, et al. miRNA profiling of naive, effector and memory CD8 $\mathrm{T}$ cells. PLoS One. 2007;2(10):e1020.

\section{Received: December 19, 2013}

